\title{
Common genetic variant rs3802842 in 11q23 contributes to colorectal cancer risk in Chinese population
}

\author{
Chunze Zhang ${ }^{1, *}$, Xichuan Li $^{2, *}$, Weihua Zhang ${ }^{1}$, Yijia Wang ${ }^{3}$, Guanwei Fan ${ }^{4,5}$, \\ Wenhong Wang ${ }^{6}$, Shuo Chen ${ }^{1}$, Hai Qin ${ }^{1}$ and Xipeng Zhang ${ }^{1}$ \\ ${ }^{1}$ Department of Colorectal Surgery, Tianjin Union Medical Center, Tianjin 300121, China \\ ${ }^{2}$ Department of Immunology, Biochemistry and Molecular Biology, 2011 Collaborative Innovation Center of Tianjin for Medical \\ Epigenetics, Tianjin Key Laboratory of Medical Epigenetics, Tianjin Medical University, Tianjin 300070, China \\ ${ }^{3}$ Department of Pathology, Tianjin Union Medical Center, Tianjin 300121, China \\ ${ }^{4}$ First Teaching Hospital of Tianjin University of Traditional Chinese Medicine, Tianjin 300193, China \\ ${ }^{5}$ State Key Laboratory of Modern Chinese Medicine, Tianjin University of Traditional Chinese Medicine, Tianjin 300193, China \\ ${ }^{6}$ Department of Imaging, Tianjin Union Medical Center, Tianjin 300121, China \\ "These authors have contributed equally to this work
}

Correspondence to: Xipeng Zhang, email: xipengzhangtj@163.com

Keywords: colorectal cancer, rs3802842, meta-analysis, Chinese population

Received: April 18,2017 Accepted: June 28, $2017 \quad$ Published: July 31, 2017

Copyright: Zhang et al. This is an open-access article distributed under the terms of the Creative Commons Attribution License 3.0 (CC BY 3.0), which permits unrestricted use, distribution, and reproduction in any medium, provided the original author and source are credited.

\section{ABSTRACT}

A genome-wide association study identified a common genetic variant rs3802842 at $11 \mathrm{q} 23$ to be associated with $\mathrm{CRC}$ risk with $\mathrm{OR}=1.1$ and $P=5.80 \mathrm{E}-10$ in European population. In Chinese population, several genetic association studies have investigated the association between rs3802842 variant and CRC risk. However these studies reported both positive and negative association results. It is still necessary to evaluate a specific variant in a specific population, which would be informative to reveal the disease mechanism. Until recently, there is no a systemic study to evaluate the potential association between rs 3802842 and CRC risk in Chinese population by a meta-analysis method. Here, we aim to evaluate this association in Chinese population by a meta-analysis method using 12077 samples including 5816 CRC cases and 6261 controls. We identified the $T$ allele of rs3802842 to be significantly related with an increase CRC risk $(P=2.22 E-05, O R=1.14,95 \% C I$ 1.07-1.21 $)$ in Chinese population.

\section{INTRODUCTION}

Colorectal cancer $(\mathrm{CRC})$ is the third most common type of cancer in the world $[1,2]$. CRC is considered to be caused by the interactions between genetic variants and environmental factors [3-6]. In recent years, large-scale genome-wide association studies (GWAS) have identified some novel common CRC genetic variants [7-13]. Tenesa et al. identified a previously unreported common genetic variant rs 3802842 on $11 \mathrm{q} 23$ to be associated with CRC risk with $\mathrm{OR}=1.1$ and $P=5.80 \mathrm{E}-10$ in European population [8].

Evidence shows that allele frequencies, specific linkage disequilibrium structure, and special genetic and environmental backgrounds may cause the risk alleles variation to $\mathrm{CRC}$ risk in different populations [14]. Meanwhile, the incidence of CRC is different in populations [15-17]. In Chinese population, several genetic association studies have investigated the association between rs3802842 variant and CRC risk. However these studies reported both positive [18-20] and negative [21-23] association results. It is still necessary to evaluate a specific variant in a specific population, which would be informative to reveal the disease mechanism [14]. Until recently, there is no a systemic study to evaluate the potential association between rs 3802842 and CRC risk in Chinese population by a meta-analysis method. Here, we aim to evaluate this association in Chinese population by a meta-analysis method. 


\section{RESULTS}

\section{Study characteristics}

In the PubMed database, we got 36 potential studies using the key words 'rs3802842' + 'colorectal cancer' (up to June 26,2017$)$. We screened the 36 potential article abstracts, and excluded 20 articles. We further screened the remaining 16 potential full articles, and excluded 11 articles. Meanwhile, we got another one article using Google Scholar database. In the end, we selected six independent case-control association studies in Chinese population [18-23]. All these six studies evaluated the potential association between rs3802842 and CRC risk in Chinese population with a total of 11210 samples including 4794 CRC cases and 6416 controls. All these studies did not depart from Hardy-Weinberg equilibrium. The main characteristics of these six studies are described in Table 1.

\section{Heterogeneity test}

Using $\mathrm{C}$ vs. A model, we identified significant heterogeneity in all the selected six studies with $\mathrm{Chi}^{2}=$ $15.03, \mathrm{df}=5(\mathrm{P}=0.01) ; \mathrm{I}^{2}=67 \%$. Using $\mathrm{CC}$ vs. $\mathrm{CA}+\mathrm{AA}$ model, we did not identified significant heterogeneity in four of these six studies with $\mathrm{Chi}^{2}=1.90, \mathrm{df}=3(\mathrm{P}=$ $0.59) ; \mathrm{I}^{2}=0 \%$. Using CC $+\mathrm{CA}$ vs. AA model, we identified significant heterogeneity in four of these six studies with $\mathrm{Chi}^{2}=10.43, \mathrm{df}=3(\mathrm{P}=0.02) ; \mathrm{I}^{2}=71 \%$. The detailed information is described in Figure 1.

\section{Meta-analysis}

In $\mathrm{C}$ vs. A model, we applied the random-effect model to perform the meta-analysis, which indicated significant association between rs3802842 C allele and CRC risk with $P=3.00 \mathrm{E}-04$, OR (odds ratio) $=1.21$, and $95 \%$ CI (confidence interval) $[1.09,1.35]$. In CC vs. CA+AA model, we applied the fixed-effect model to perform the meta-analysis, which indicated significant association between rs3802842 CC genotype and CRC risk with $P=2.22 \mathrm{E}-07, \mathrm{OR}=1.39$, and $95 \% \mathrm{CI}[1.23,1.57]$. In $\mathrm{CC}+\mathrm{CA}$ vs. AA model, we applied the random-effect model to perform the meta-analysis, which indicated significant association between rs3802842 CC+CA genotype and $\mathrm{CRC}$ risk with $P=9.00 \mathrm{E}-03, \mathrm{OR}=1.37$, and $95 \%$ CI $[1.08,1.74]$. The detailed information is described in Figure 1.

\section{Publication bias analysis}

The possible publication bias of meta-analysis is evaluated by both funnel plot and a regression based statistical approach. Based on the shapes of funnel plots, we did not observe any asymmetric signal in all these three models as described in Figure 2 (Figure 2 illustrates no publication bias for the association of the rs 3802842 with CRC risk.). The regression method also did not display any evidence of obvious publication bias with $P=0.81$ for $\mathrm{C}$ vs. A model.

\section{Sensitivity analysis}

A leave-one-out sensitivity analysis showed that the pooled ORs were not significantly changed when all these studies were excluded one by one, which indicated that the meta-analysis results were robust and reliable (data not shown).

\section{Subgroup analysis}

In Han Chinese subgroup, we did not identified significant heterogeneity in these four studies with $\mathrm{Chi}^{2}$ $=4.21, \mathrm{df}=3(\mathrm{P}=0.24) ; \mathrm{I}^{2}=29 \%$. We applied the fixedeffect model to perform the meta-analysis, which indicated significant association between rs $3802842 \mathrm{C}$ allele and CRC risk with $P=9.19 \mathrm{E}-15, \mathrm{OR}=1.31$, and $95 \%$ CI $[1.22$, 1.40]. In the combined Hong Kong Chinese and Taiwan Chinese subgroup, we did not identified significant heterogeneity in these four studies with Heterogeneity: $\mathrm{Chi}^{2}=0.00, \mathrm{df}=1(\mathrm{P}=0.98) ; \mathrm{I}^{2}=0 \%$. We applied the fixed-effect model to perform the meta-analysis, which indicated no significant association between rs $3802842 \mathrm{C}$ allele and CRC risk with $P=0.08, \mathrm{OR}=1.08$, and $95 \% \mathrm{CI}$ $[0.99,1.19]$.

\section{DISCUSSION}

Tenesa et al. identified rs 3802842 to be significantly associated with CRC risk [8]. In 2014, Closa et al. analyzed 144 samples and successfully identified that $\mathrm{CRC}$ risk loci identified in large-scale GWAS may regulate the expression of nearby genes, which may be candidate targets for developing new strategies for prevention or therapy [24]. Interestingly, rs3802842 in $11 \mathrm{q} 23.1$ could significantly regulate the expression of C11 orf53, COLCA1 (C11orf92) and COLCA2 (C11orf93) [24]. In 2014, Peltekova et al. analyzed 1,030 CRC cases and 1,061 controls [25]. They also reported COLCA1 and COLCA2 to be regulated by rs 3802842 variant [25]. Using tissue microarray analysis, they further showed that rs3802842 was significantly associated with levels of COLCA1 and COLCA2 in the lamina propria [25]. All these findings indicate that rs 3802842 is associated with $\mathrm{CRC}$ risk and regulate the expression of COLCA1 and COLCA2 genes, which may be involved in pathogenesis of CRC.

Until recently, six independent case-control association studies have been conducted to investigate the association between rs3802842 and CRC risk in Chinese population. Three studies reported positive association results [18-20], and another three studies reported 


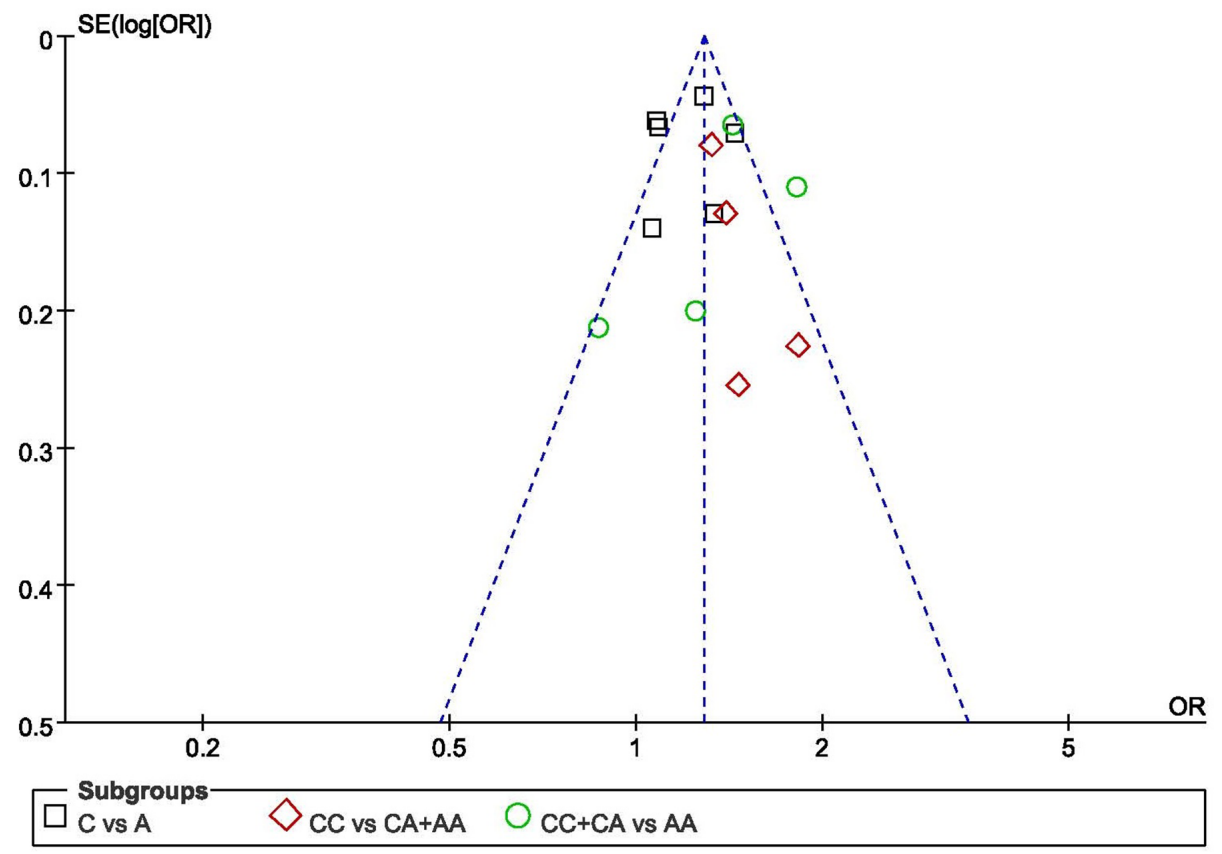

Figure 2: Funnel plot for the recessive model to analyze publication bias of the association of the rs3802842 polymorphism with CRC risk in Chinese population.

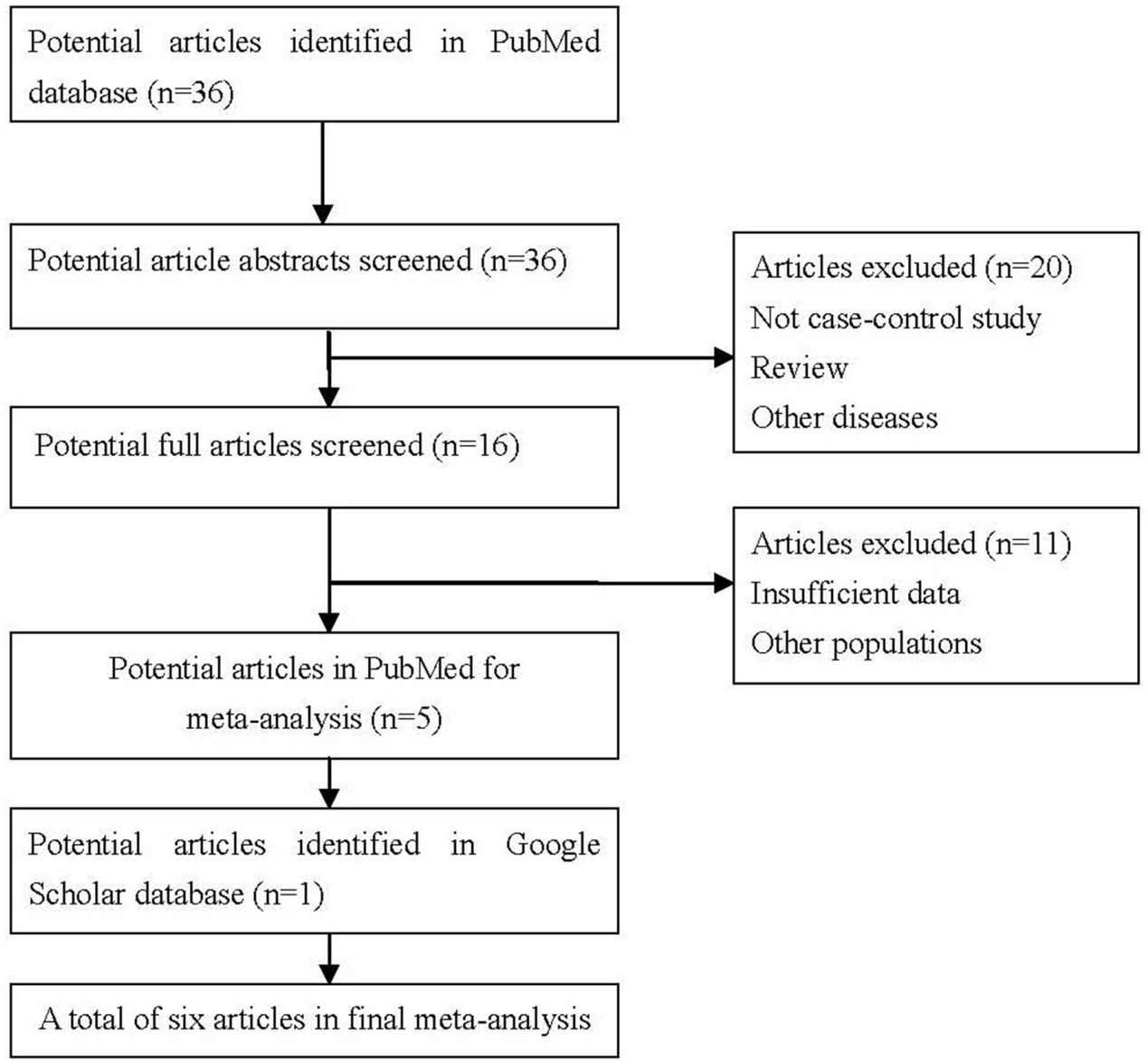

Figure 3: PRISMA flow-diagram showing identification and selection of the pertinent studies for the present metaanalysis. 
negative association results [21-23]. In this study, we evaluated this association by a meta-analysis using 11210 samples including 4794 CRC cases and 6416 controls, and identified significant association between rs3802842 and CRC in Chinese population.

In our study, we identified significant heterogeneity in these six genetic association studies. We think this may be caused by the substantial genetic variation in Han Chinese population [26]. Chen et al. analyzed 350,000 genetic variants in over 6000 Han Chinese samples from ten provinces of China [26]. Their results showed a onedimensional "north-south" population structure and a correlation between geography and the genetic structure of the Han Chinese [26].

Considering the significant heterogeneity, we further performed a subgroup analysis in the Han Chinese subgroup, and the combined Hong Kong and Taiwan Chinese subgroup. The results are consistent with previous findings. The heterogeneity in Han Chinese subgroup ( $\mathrm{I}^{2}$ $=29 \%$ ) is higher compared with that in combined Hong Kong and Singapore Chinese subgroup $\left(\mathrm{I}^{2}=0 \%\right)$. Metaanalysis further showed the rs3802842 variant to be significantly associated with CRC risk in Han Chinese subgroup, but not in the combined Hong Kong and Taiwan Chinese subgroup.

In 2012, Zou et al. performed a replication study and meta-analysis [19]. In their study, the only selected 4 independent studies in Asian population including 3 independent studies in Chinese population [19]. Here, we selected 6 independent studies in Chinese population to evaluate the association between rs3802842 variant and $\mathrm{CRC}$ risk with lager sample size compared with previous study [19]. Our results are consistent with previous findings that there is obvious between-study heterogeneity [19].

\section{MATERIALS AND METHODS}

\section{Search strategy}

Two reviewers independently selected the potential studies by systematically searching the PubMed database (https:/www.ncbi.nlm.nih.gov/pubmed/) using the key words 'rs3802842' + 'colorectal cancer' ( $\mathrm{n}=36$, up to June 26,2017 ). We also manually examined additional studies from the references cited in the original literature using Google Scholar database (https://scholar.google.com/), especially all associated publications citing the original CRC GWAS [8]. Here, we limit the following analysis in Chinese population including a native or inhabitant of China or a person of Chinese ancestry. If any two casecontrol studies overlap with each other, we select the one with the largest sample size in meta-analysis. More detailed information is described in Figure 3, which is a flow diagram of the process used to select eligible studies.

\section{Study inclusion criteria}

The potential genetic association studies should (1) be a case-control design in Chinese population; (2) evaluate the association between rs3802842 and CRC risk; (3) provide the original genotype number, or allele number, or odds ratio (OR) with $95 \%$ confidence interval (CI) for one of the three genetic models; or (4) provide sufficient data to calculate the genotype number, or allele number, or OR and 95\% CI for one of these three genetic models. We excluded those studies that did not meet the inclusion criteria in following meta-analysis.

\section{Data extraction}

We extracted (1) the name of the first author; (2) the year of publication; (3) the population; (4) the numbers of CRC cases and controls. Two reviewers independently extracted the data carefully. Meanwhile, a third reviewer resolved any disagreement. More detailed information has been widely described in previous studies using the metaanalysis methods [27-44].

\section{Statistical analysis}

In brief, we used Review Manager 5.1 to investigate the potential heterogeneity in all the selected studies by a Cochran's Q test, calculate the pooled OR by a fixed effect model or a random-effect model based on the potential heterogeneity, determine the significance of pooled OR by a $\mathrm{Z}$ test.

We calculated the Hardy-Weinberg equilibrium by a chi-square test in $\mathrm{R}$ program, if one study provides the control genotype number $[45,46]$. If not, we extracted the Hardy-Weinberg equilibrium information from the original studies. Here, three genetic models were selected including $\mathrm{C}$ vs. $\mathrm{A}, \mathrm{CC}$ vs. $\mathrm{CA}+\mathrm{AA}$, and $\mathrm{CC}+\mathrm{CA}$ vs. $\mathrm{AA}$. More detailed information has been widely described in previous studies using meta-analysis methods [27-44, 47, 48].

We investigate potential publication bias by a funnel plot based approach, and a regression based statistical approach proposed by Egger. We performed a sensitivity analysis by a leave-one-out method [49]. We evaluated the influence of each study on pooled OR by omitting each study one at a time [49]. All statistical analyses were performed using Review Manager 5.1 or R, and the significance level is 0.05 .

\section{Subgroup analysis}

We performed a subgroup analysis in the Han Chinese subgroup including four studies, and in the combined Hong Kong Chinese and Taiwan Chinese subgroup including two studies using $\mathrm{C}$ vs. A model. 


\section{ACKNOWLEDGMENTS}

This study was funded by Tianjin Health Bureau Science Foundation Key Project (2014KR14), Tianjin People's Hospital (2016YJZD006), and Tianjin Health and Family Planning Commission (14KG108, 2010KG206 and 16KG154).

\section{CONFLICTS OF INTEREST}

The authors declare no competing financial interest.

\section{REFERENCES}

1. Vinson KE, George DC, Fender AW, Bertrand FE, Sigounas G. The Notch pathway in colorectal cancer. Int J Cancer. 2016; 138:1835-42.

2. Quan B, Qi X, Yu Z, Jiang Y, Liao M, Wang G, Feng R, Zhang L, Chen Z, Jiang Q, Liu G. Pathway analysis of genome-wide association study and transcriptome data highlights new biological pathways in colorectal cancer. Mol Genet Genomics. 2015; 290:603-10.

3. Liao M, Wang G, Quan B, Qi X, Yu Z, Feng R, Zhang L, Jiang Y, Zhang Y, Liu G. Analyzing large-scale samples confirms the association between rs16892766 polymorphism and colorectal cancer susceptibility. Sci Rep. 2015; 5:7957.

4. He D, Ma L, Feng R, Zhang L, Jiang Y, Zhang Y, Liu G. Analyzing large-scale samples highlights significant association between rs10411210 polymorphism and colorectal cancer. Biomed Pharmacother. 2015; 74:164-8.

5. Han P, Liu G, Lu X, Cao M, Yan Y, Zou J, Li X, Wang G. CDH1 rs9929218 variant at $16 \mathrm{q} 22.1$ contributes to colorectal cancer susceptibility. Oncotarget. 2016; 7:4727886. https://doi.org/10.18632/oncotarget.9758.

6. Smith CG, Fisher D, Harris R, Maughan TS, Phipps AI, Richman S, Seymour M, Tomlinson I, Rosmarin D, Kerr D, Chan AT, Peters U, Newcomb PA, et al. Analyses of 7,635 patients with colorectal cancer using independent training and validation cohorts show that rs9929218 in CDH1 is a prognostic marker of survival. Clin Cancer Res. 2015; 21:3453-61.

7. Tomlinson I, Webb E, Carvajal-Carmona L, Broderick P, Kemp Z, Spain S, Penegar S, Chandler I, Gorman M, Wood W, Barclay E, Lubbe S, Martin L, et al. A genome-wide association scan of tag SNPs identifies a susceptibility variant for colorectal cancer at 8q24.21. Nat Genet. 2007; 39:984-8.

8. Tenesa A, Farrington SM, Prendergast JG, Porteous ME, Walker M, Haq N, Barnetson RA, Theodoratou E, Cetnarskyj R, Cartwright N, Semple C, Clark AJ, Reid FJ, et al. Genome-wide association scan identifies a colorectal cancer susceptibility locus on 11q23 and replicates risk loci at 8q24 and 18q21. Nat Genet. 2008; 40:631-7.
9. Tomlinson IP, Webb E, Carvajal-Carmona L, Broderick P, Howarth K, Pittman AM, Spain S, Lubbe S, Walther A, Sullivan K, Jaeger E, Fielding S, Rowan A, et al. A genome-wide association study identifies colorectal cancer susceptibility loci on chromosomes 10p14 and 8q23.3. Nat Genet. 2008; 40:623-30.

10. Houlston RS, Webb E, Broderick P, Pittman AM, Di Bernardo MC, Lubbe S, Chandler I, Vijayakrishnan J, Sullivan K, Penegar S, Carvajal-Carmona L, Howarth K, Jaeger E, et al. Meta-analysis of genome-wide association data identifies four new susceptibility loci for colorectal cancer. Nat Genet. 2008; 40:1426-35.

11. Schumacher FR, Schmit SL, Jiao S, Edlund CK, Wang H, Zhang B, Hsu L, Huang SC, Fischer CP, Harju JF, Idos GE, Lejbkowicz F, Manion FJ, et al. Genome-wide association study of colorectal cancer identifies six new susceptibility loci. Nat Commun. 2015; 6:7138.

12. Jia WH, Zhang B, Matsuo K, Shin A, Xiang YB, Jee SH, Kim DH, Ren Z, Cai Q, Long J, Shi J, Wen W, Yang G, et al. Genome-wide association analyses in East Asians identify new susceptibility loci for colorectal cancer. Nat Genet. 2013; 45:191-6.

13. Zhang B, Jia WH, Matsuda K, Kweon SS, Matsuo K, Xiang YB, Shin A, Jee SH, Kim DH, Cai Q, Long J, Shi J, Wen W, et al. Large-scale genetic study in East Asians identifies six new loci associated with colorectal cancer risk. Nat Genet. 2014; 46:533-42.

14. Akbari Z, Safari-Alighiarloo N, Taleghani MY, Mirfakhar FS, Asadzadeh Aghdaei H, Vahedi M, Irani Shemirani A, Nazemalhosseini-Mojarad E, Zali MR. Polymorphism of SMAD7 gene (rs2337104) and risk of colorectal cancer in an Iranian population: a case-control study. Gastroenterol Hepatol Bed Bench. 2014; 7:198-205.

15. Simon MS, Thomson CA, Pettijohn E, Kato I, Rodabough RJ, Lane D, Hubbell FA, O'Sullivan MJ, Adams-Campbell L, Mouton CP, Abrams J, Chlebowski RT. Racial differences in colorectal cancer incidence and mortality in the Women's Health Initiative. Cancer Epidemiol Biomarkers Prev. 2011; 20:1368-78.

16. Virk R, Gill S, Yoshida E, Radley S, Salh B. Racial differences in the incidence of colorectal cancer. Can J Gastroenterol. 2010; 24:47-51.

17. Whittemore AS. Colorectal cancer incidence among Chinese in North America and the People's Republic of China: variation with sex, age and anatomical site. Int $\mathrm{J}$ Epidemiol. 1989; 18:563-8.

18. Xiong F, Wu C, Bi X, Yu D, Huang L, Xu J, Zhang T, Zhai K, Chang J, Tan W, Cai J, Lin D. Risk of genome-wide association study-identified genetic variants for colorectal cancer in a Chinese population. Cancer Epidemiol Biomarkers Prev. 2010; 19:1855-61.

19. Zou L, Zhong R, Lou J, Lu X, Wang Q, Yang Y, Xia J, Ke J, Zhang T, Sun Y, Liu L, Cui Y, Xiao H, et al. Replication study in Chinese population and meta-analysis supports 
association of the 11q23 locus with colorectal cancer. PLoS One. 2012; 7:e45461.

20. Duan X, Li X, Lou H, Geng T, Jin T, Liang P, Li S, Long Y, Chen C. Genetic association of PLCE1, C11orf92C11orf93, and NOC3L with colorectal cancer risk in the Han population. Tumour Biol. 2014; 35:1813-7.

21. Ho JW, Choi SC, Lee YF, Hui TC, Cherny SS, GarciaBarcelo MM, Carvajal-Carmona L, Liu R, To SH, Yau TK, Chung CC, Yau CC, Hui SM, et al. Replication study of SNP associations for colorectal cancer in Hong Kong Chinese. Br J Cancer. 2011; 104:369-75.

22. Li FX, Yang XX, Hu NY, Du HY, Ma Q, Li M. Singlenucleotide polymorphism associations for colorectal cancer in southern Chinese population. Chin J Cancer Res. 2012; 24:29-35.

23. Yang CY, Lu RH, Lin CH, Jen CH, Tung CY, Yang SH, Lin JK, Jiang JK. Single nucleotide polymorphisms associated with colorectal cancer susceptibility and loss of heterozygosity in a Taiwanese population. PLoS One. 2014; 9:e100060.

24. Closa A, Cordero D, Sanz-Pamplona R, Sole X, Crous-Bou M, Pare-Brunet L, Berenguer A, Guino E, Lopez-Doriga A, Guardiola J, Biondo S, Salazar R, Moreno V. Identification of candidate susceptibility genes for colorectal cancer through eQTL analysis. Carcinogenesis. 2014; 35:2039-46.

25. Peltekova VD, Lemire M, Qazi AM, Zaidi SH, Trinh QM, Bielecki R, Rogers M, Hodgson L, Wang M, D'Souza DJ, Zandi S, Chong T, Kwan JY, et al. Identification of genes expressed by immune cells of the colon that are regulated by colorectal cancer-associated variants. Int J Cancer. 2014; 134:2330-41.

26. Chen J, Zheng H, Bei JX, Sun L, Jia WH, Li T, Zhang F, Seielstad M, Zeng YX, Zhang X, Liu J. Genetic structure of the Han Chinese population revealed by genome-wide SNP variation. Am J Hum Genet. 2009; 85:775-85.

27. Hu Y, Zheng L, Cheng L, Zhang Y, Bai W, Zhou W, Wang T, Han Z, Zong J, Jin S, Zhang J, Liu G, Jiang Q. GAB2 rs2373115 variant contributes to Alzheimer's disease risk specifically in European population. J Neurol Sci. 2017; 375:18-22.

28. Liu G, Zhang S, Cai Z, Li Y, Cui L, Ma G, Jiang Y, Zhang L, Feng R, Liao M, Chen Z, Zhao B, Li K. BIN1 gene rs744373 polymorphism contributes to Alzheimer's disease in East Asian population. Neurosci Lett. 2013; 544:47-51.

29. Liu G, Wang H, Liu J, Li J, Li H, Ma G, Jiang Y, Chen Z, Zhao B, Li K. The CLU gene rs11136000 variant is significantly associated with Alzheimer's disease in Caucasian and Asian populations. Neuromolecular Med. 2014; 16:52-60.

30. Song Q, Zhu B, Hu W, Cheng L, Gong H, Xu B, Zheng X, Zou L, Zhong R, Duan S, Chen W, Rui R, Wu J, et al. A common SMAD7 variant is associated with risk of colorectal cancer: evidence from a case-control study and a meta-analysis. PLoS One. 2012; 7:e33318.

31. Yao K, Hua L, Wei L, Meng J, Hu J. Correlation between CASC8, SMAD7 polymorphisms and the susceptibility to colorectal cancer: an updated meta-analysis based on GWAS results. Medicine (Baltimore). 2015; 94:e1884.

32. Hong Y, Wu G, Li W, Liu D, He K. A comprehensive metaanalysis of genetic associations between five key SNPs and colorectal cancer risk. Oncotarget. 2016; 7:73945-59. https://doi.org/10.18632/oncotarget.12154.

33. Sagoo GS, Little J, Higgins JP. Systematic reviews of genetic association studies. Human Genome Epidemiology Network. PLoS Med. 2009; 6:e28.

34. Kavvoura FK, Ioannidis JP. Methods for meta-analysis in genetic association studies: a review of their potential and pitfalls. Hum Genet. 2008; 123:1-14.

35. Gwinn M, Ioannidis JP, Little J, Khoury MJ. Editorial: updated guidance on human genome epidemiology (HuGE) reviews and meta-analyses of genetic associations. Am J Epidemiol. 2014; 180:559-61.

36. Li Y, Song D, Jiang Y, Wang J, Feng R, Zhang L, Wang G, Chen Z, Wang R, Jiang Q, Liu G. CR1 rs3818361 polymorphism contributes to Alzheimer's disease susceptibility in Chinese population. Mol Neurobiol. 2016; 53:4054-9.

37. Zhang S, Li X, Ma G, Jiang Y, Liao M, Feng R, Zhang L, Liu J, Wang G, Zhao B, Jiang Q, Li K, Liu G. CLU rs9331888 polymorphism contributes to Alzheimer's disease susceptibility in Caucasian but not East Asian populations. Mol Neurobiol. 2016; 53:1446-51.

38. Li X, Shen N, Zhang S, Liu J, Jiang Q, Liao M, Feng R, Zhang L, Wang G, Ma G, Zhou H, Chen Z, Jiang Y, et al. CD33 rs3865444 polymorphism contributes to Alzheimer's disease susceptibility in Chinese, European, and North American populations. Mol Neurobiol. 2015; 52:414-21.

39. Chen $\mathrm{H}, \mathrm{Wu}$ G, Jiang Y, Feng R, Liao M, Zhang L, Ma G, Chen Z, Zhao B, Li K, Yu C, Liu G. Analyzing 54,936 samples supports the association between CD2AP rs9349407 polymorphism and Alzheimer's disease susceptibility. Mol Neurobiol. 2015; 52:1-7.

40. Zhang S, Zhang D, Jiang Y, Wu L, Shang H, Liu J, Feng R, Liao M, Zhang L, Liu Y, Liu G, Li K. CLU rs2279590 polymorphism contributes to Alzheimer's disease susceptibility in Caucasian and Asian populations. J Neural Transm (Vienna). 2015; 122:433-9.

41. Shen N, Chen B, Jiang Y, Feng R, Liao M, Zhang L, Li F, Ma G, Chen Z, Zhao B, Li K, Liu G. An updated analysis with 85,939 samples confirms the association between CR1 rs6656401 polymorphism and Alzheimer's disease. Mol Neurobiol. 2015; 51:1017-23.

42. Liu G, Li F, Zhang S, Jiang Y, Ma G, Shang H, Liu J, Feng R, Zhang L, Liao M, Zhao B, Li K. Analyzing large-scale samples confirms the association between the 
ABCA7 rs3764650 polymorphism and Alzheimer's disease susceptibility. Mol Neurobiol. 2014; 50:757-64.

43. Zhang $\mathrm{C}$, Li X, Fu W, Wang Y, Wang T, Wang W, Chen S, Qin H, Zhang X. SMAD7 rs4939827 variant contributes to colorectal cancer risk in Chinese population. Oncotarget. 2017; 8:41125-31. https://doi.org/10.18632/ oncotarget. 17065.

44. Liu G, Xu Y, Jiang Y, Zhang L, Feng R, Jiang Q. PICALM rs3851179 variant confers susceptibility to Alzheimer's disease in Chinese population. Mol Neurobiol. 2017; 54:3131-6.

45. Liu G, Zhang S, Cai Z, Ma G, Zhang L, Jiang Y, Feng R, Liao M, Chen Z, Zhao B, Li K. PICALM gene rs3851179 polymorphism contributes to Alzheimer's disease in an Asian population. Neuromolecular Med. 2013; 15:384-8.

46. Liu G, Zhang L, Feng R, Liao M, Jiang Y, Chen Z, Zhao B, Li K. Lack of association between PICALM rs3851179 polymorphism and Alzheimer's disease in Chinese population and APOEepsilon4-negative subgroup. Neurobiol Aging. 2013; 34:1310. e9-10.

47. Areeshi MY, Mandal RK, Akhter N, Dar SA, Jawed A, Wahid M, Mahto H, Panda AK, Lohani M, Haque S. A meta-analysis of MBL2 polymorphisms and Tuberculosis risk. Sci Rep. 2016; 6:35728.

48. Rao S, Yao Y, Ryan J, Li T, Wang D, Zheng C, Xu Y, Xu Q. Common variants in FKBP5 gene and major depressive disorder (MDD) susceptibility: a comprehensive metaanalysis. Sci Rep. 2016; 6:32687.

49. Liu H, Huang J, Dou M, Liu Y, Xiao B, Liu X, Huang Z. Variants in the IL7RA gene confer susceptibility to multiple sclerosis in Caucasians: evidence based on 9734 cases and 10436 controls. Sci Rep. 2017; 7:1207. 